\title{
Differences in Carotid Intima-Media Thickness (CIMT) In Patients With Newly Diagnosed Hypertension, and Chronic Hypertensive Patients Treated by Calcium Channel Blockers (CCB) or Angiotensin Converting Enzyme (ACE)-Inhibitors
}

\author{
Ni Luh Tantri ${ }^{1}$, Achmad Rudijanto², Nur Samsu33, Wursito ${ }^{4}$
}

\author{
${ }^{1}$ Department of Internal Medicine, Faculty of Medicine, Universitas Brawijaya - dr. Saiful Anwar Hospital, Malang \\ ${ }^{2}$ Division of Endocrinology, Metabolic and Diabetes, Department of Internal Medicine, Faculty of Medicine, Universitas Brawijaya - dr. Saiful Anwar \\ Hospital, Malang \\ ${ }^{3}$ Division of Nephrology and Hypertension, Department of Internal Medicine, Faculty of Medicine, Universitas Brawijaya - dr. Saiful Anwar Hospital, \\ Malang
}

${ }^{4}$ Department of Cardiology, Faculty of Medicine, Universitas Brawijaya - dr. Saiful Anwar Hospital, Malang

\section{A R T I C L E I N F O}

Corresponding Author:

Ni Luh Tantri

Department of Internal Medicine,

Faculty of Medicine, Universitas

Brawijaya, dr. Saiful Anwar, General

Hospital, Malang.

Email: niluh_tantri_dr@yahoo.com

- - - - - - - - - - - - - - -

https://doi.org/10.2776/u

b.crjim.2020.001.01.2

Received on Feb 29th, 2020;

Revised on March 7th, 2020;

Accepted on March 16 $6^{\text {th }}, 2020$

\section{A B S T R A C T}

Hypertension is a significant risk factor for cardiovascular diseases. It closely related to the inflammatory process and resulting in chronic inflammation, which had a critical role in the progression of atherosclerosis. Carotid Intima-Media Thickness (CIMT) was known as a surrogate marker of atherosclerosis. Anti-hypertensive drugs are expected to affect CIMT. Aim: to examine the difference CIMT between newly diagnosed hypertension and chronic hypertensive treated by ACE-I or CCB. Method: this cross-sectional study was conducted on 12 newly diagnosed hypertensive patients (control or group 1), 9 hypertensive patients treated by CCB (group 2), and 9 hypertensive patients treated by ACE-I (group 3). Their hypertensive condition was controlled at least for 6 months. We compared CIMT of patients and Tumour Necrosis Factor Alfa (TNF- $\alpha$ ) also Interleukin- 6 (IL-6) among the groups. Result: there was a significant difference in CIMT between the group 1 and 2 ( 0.86 vs $0.70 ; p=0.027)$, group 1 and 3 ( 0.86 vs $0.69 ; p=0.018)$. There was no significant difference between group 2 and 3 ( 0.70 vs $0.69 ; p=0.88)$. There was no association between CIMT and TNF- $\alpha$, IL-6, Low-Density Lipoprotein (LDL), triglycerides (TGs) levels, and body mass index (BMI), systolic blood pressure. Conclusion: we found that the CIMT of the control group was thicker than those of the treatment groups. Moreover, differences in the thickness of CIMT of the three groups were not associsted with level of TNF- $\alpha$, IL-6, TG, and LDL, also BMI, and systolic blood pressure.

Keywords: hypertension, atherosclerosis, CIMT, ACE-inhibitors, Calcium Channel Blockers

\section{N T R O D U C T I O N}

Hypertension is a condition that occurs due to interactions between genetic factors and environmental factors.[1,2] In its development, the vascular inflammation process is known to have a role in the pathophysiology of essential hypertension. ${ }^{[3]}$ Inflammation has a chemokine receptor that plays a critical role in the process of adhesion and leukocyte recruitment in endothelial cells.[4,5] C - Reactive protein (CRP), Interleukin-6 (IL-6), and Tumour Necrosis Factor-alpha (TNF- $\alpha$ ) are independent risk factors for the development of hypertension.[6] Hypertension also causes a chronic inflammation, which is suspected to be very closely related to vascular inflammation, which we recently knew to have an essential role in the process of atherosclerosis.[7,8,9]

Carotid artery intima-media thickness (IMT) or carotid artery thickness and carotid artery media are markers of atherosclerosis ${ }^{[10]}$ that are independently associated with cardiovascular events. ${ }^{[11,14]}$ We obtained the pieces of evidence from various clinical studies that support a direct effect on the vascular of Angiotensin Converting Enzyme Inhibitors (ACE-I) Inhibition. The Trial on Reversing Endothelial Dysfunction (TREND) study showed that 
after 6 months of therapy with ACE-I, Quinapril could repair endothelial dysfunction in patients given by acetylcholine to provoke vasoconstriction. ${ }^{[15]}$

Referring to the background of this present study, we encountered various studies that have developed to look for Beyond Blood Pressure Lowering Effect of other anti-hypertensive drugs.[16] Some studies explained Calcium Channel Blocker (CCB) could inhibit the progression of atherosclerosis and reduce the risk of cardiovascular disease.[17]

Considering the mechanism of action of CCB drugs serves intracellular calcium ions, where calcium ions are essential second messenger in the cell signaling process, we expected that CCB has a role that is more than anti-hypertension. Calcium ions can stimulate the production of endothelial nitric oxide (eNOS), prostaglandins, and Nitric Oxide (NO) through calcium-calmodulin complex bonds. It has a role not only as potent vasodilators but also have antiplatelet aggregation effects. It also prevents the proliferation of smooth muscle cells (SMC) that play a crucial role as an atheroprotective factor.[18]

We conducted this study to examine the thickness of carotid intima-media in hypertensive patients who had not received therapy, and hypertensive patients who had received ACE-I therapy or CCB therapy. We hypothesize that there is a difference in thickness of carotid intima-media between the control group and the two treatment groups.

\section{E T H O D S}

\section{Study Design}

We conducted this study with a crosssectional approach to compare CIMT, TNF- $\alpha$, and IL6 between hypertensive patients with stage 1 and 2 hypertension who had never received therapy and who had received ACE-I or CCB treatment at Saiful Anwar Hospital Malang, for at lest 6-months. The hypertensive patients were selected from those referred to the outpatient clinic in this hospital. We undertook patients using the following sampling method. The inclusion criteria were all patients with stage 1 and 2 hypertension who had never received therapy and who had received ACE-I or CCB treatment, at least, for 6 months. We called the first group as a control group (group 1). The second group with ACE-I therapy called as group 2 . The last group with CCB treatment as group 3. All groups had an age between 40 to 60 years. Exclusion criteria of all groups were patients who suffered from active infections, glomerular filtration rate (GFR) $<60 \mathrm{ml} / \mathrm{min}$, suffered from heart failure,
Systemic Lupus Erythematosus (SLE), Rheumatoid Arthritis (RA), diabetes mellitus, and using drugs that have anti-inflammatory effects.

The research protocol was approved by the local ethics committee. We had informed about the aim and the suspected benefit of the study before getting their agreements for participation. Then, participants completed and signed the written informed consent. There were no additional Interventions by us on the hypertensive patients of this study.

\section{Study Procedures}

This study collected the data from each patient with a diagnosis of hypertension based on the JNC 7 guidelines. All patients' anamnesis, physical examination, several laboratory parameters at Saiful Anwar Hospital, Malang. The electrocardiography, chest X-ray, and B-mode ultrasonography were performed to determine the thickness of CIMT. The evaluation was carried out blindly by experienced radiologists and cardiologists.

To find out factors related to differences in CIMT thickening, we noted the types of antihypertensive drugs, measured TNF- $\alpha$, IL-6, changes in body mass index (BMI), systolic blood pressure, LDL and TG levels.

\section{Statistical analysis}

Quantitative variables are expressed as a mean and standard deviation, and compared using one-way ANOVA to compare the CIMT, TNF- $\alpha$, and IL6 between the control group and two treatment groups followed by post-hoc test, LSD. Qualitative variables are expressed as percentage and compared using the Chi-square or Fisher exact test. All technical data processing results were analysed by computerization using Statistical Product and Service Solution software, IBM SPSS Statistics 20, with a significance level of $0.05(\alpha=0.05)$.

\section{R E S U L T S}

We included a total number of 30 hypertensive patients in this study. The groups were divided into three. It consists of 12 hypertensive patients who had never received therapy, 9 hypertensive patients who had received ACE-I therapy, and 9 hypertensive patients who had received CCB therapy. 


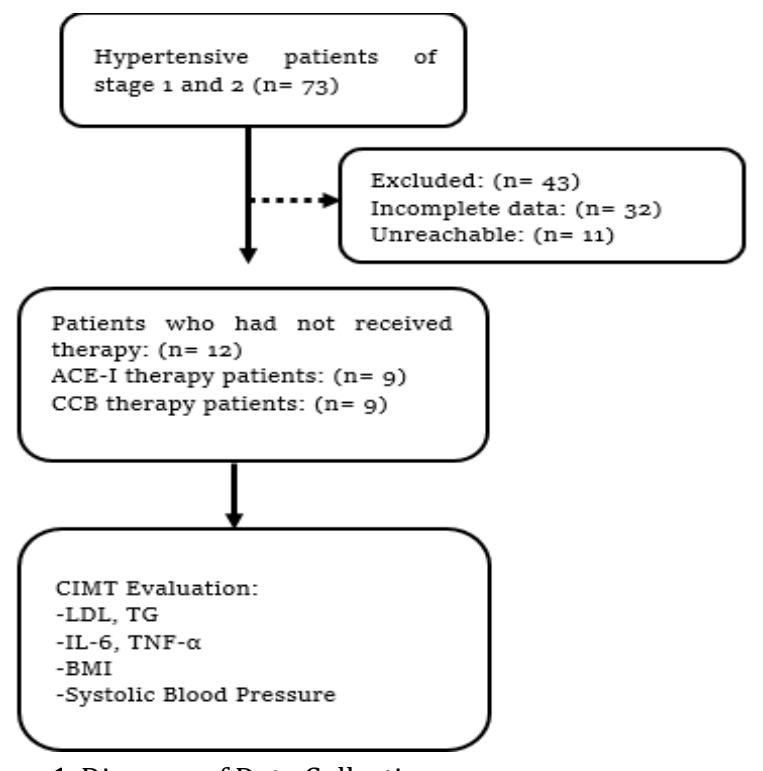

Figure 1. Diagram of Data Collection

We analyzed 30 hypertensive patients who had a complete database statistically, with the characteristics of the patients as described in figure 1. The patients consisted of 7 men (23.3\%) and 23 women $(76.7 \%)$ who attended the outpatient clinic of Saiful Anwar Hospital Malang.

There are several factors that cause CIMT thickening in a number of research subjects which were BMI $>25 \mathrm{~kg} / \mathrm{m}^{2}$ in 7 patients $(23.3 \%)$, LDL $>150 \mathrm{mg} / \mathrm{dl}$ in 12 patients $(40.0 \%)$ and $\mathrm{TG}$ $>130 \mathrm{mg} / \mathrm{dl}$ in 15 patients (50\%), systolic blood pressure $>160 \mathrm{mmHg}(86.7 \%)$.

\section{The Difference of CIMT, IL- 6 , and TNF- $\alpha$ among the} groups

We subjected all patients who met the inclusion criteria to clinical tests, laboratory evaluations, and B-mode ultrasonography to assess the thickness of the CIMT.

Table 1. Baseline Characteristics of Subjects

\begin{tabular}{llll}
\hline \multirow{2}{*}{ Variables } & \multicolumn{3}{c}{ Number of Subjects (n) } \\
\cline { 2 - 4 } & \multicolumn{1}{c}{ Control } & \multicolumn{1}{c}{ ACE-I } & \multicolumn{1}{c}{ CCB } \\
& \multicolumn{1}{c}{$(12)$} & \multicolumn{1}{c}{$(9)$} & \multicolumn{1}{c}{$(9)$} \\
\hline Male & 10 & 4 & 9 \\
Female & $48.92 \pm$ & $49.22 \pm$ & $49.44 \pm$ \\
Age $(\mathrm{yr})$ & 5.017 & 3.346 & 4.602 \\
& $29.49 \pm$ & $26.12 \pm$ & $30.11 \pm$ \\
BMI $\left(\mathrm{kg} / \mathrm{m}^{2}\right)$ & 0.87 & 1.14 & 1.52 \\
& $162.25 \pm$ & $165.00 \pm$ & $171.11 \pm$ \\
SBP $(\mathrm{mmHg})$ & 4.30 & 6.67 & 4.62 \\
& $131.83 \pm$ & $161.22 \pm$ & $136.87 \pm$ \\
LDL $(\mathrm{mg} / \mathrm{dl})$ & 11.68 & 12.83 & 8.49 \\
& $127.08 \pm$ & $156.67 \pm$ & $120.44 \pm$ \\
TG(mg/dl) & 11.05 & 22.51 & 10.60 \\
& $30.99 \pm$ & $29.24 \pm$ & $16.84 \pm$ \\
TNF- $\alpha(\mathrm{ng} / \mathrm{ml})$ & 6.48 & 8.35 & 0.08 \\
& $18.31 \pm$ & $14.48 \pm$ & $16.98 \pm$ \\
IL-6 (ng/ml) & 1.26 & 0.69 & 0.96 \\
& $0.86 \pm$ & $0.70 \pm$ & $0.69 \pm$ \\
CIMT (mm) & 0.06 & 0.04 & 0.02 \\
\hline
\end{tabular}

Data presented as mean $\pm S D, B M I$ : body mass index; $S B P$, systolic blood pressure; LDL: low-density lipoprotein; TG, triglyceride; TNFa: Tumour Necrosis Factor- $\alpha$, IL-6: interleukin-6; CIMT: carotid intimamedia thickness.

As described in the baseline characteristics of the subjects above, we obtained a different CIMT between each group. The CIMT values of patients in the three groups ranged from 0.60 to 1.30 . The lowest (minimum) value of 0.50 was obtained in the group of patients on ACE-I therapy, while we received the highest value (maximum) of 1.30 in the control group. Here is Figure 2 presents the mean (blue bar graph) showing the measures of central tendency, as well as the standard deviation.

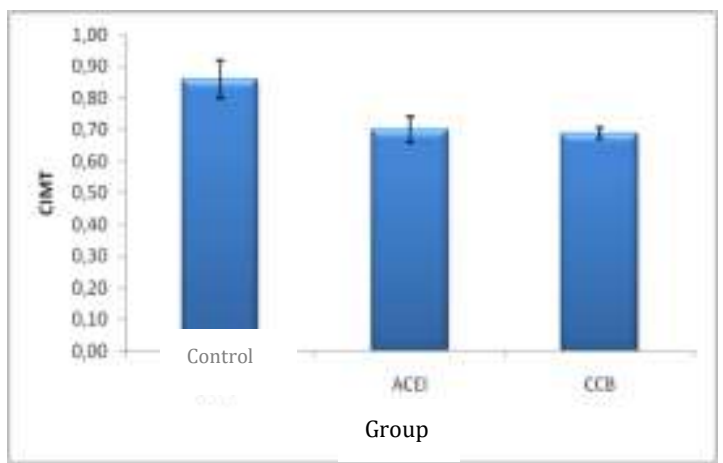

Figure 2. Histogram difference in CIMT among Groups TNF $\alpha$ : Tumour Necrosis Factor- $\alpha$, IL-6: interleukin-6; CIMT: carotid intima-media thickness.

Table 2. Differences in CMIT, TNF- $\alpha$, and IL- 6 among groups

\begin{tabular}{lcccc}
\hline & Control & ACE-I & CCB & $\begin{array}{c}\text { P } \\
\text { value* }\end{array}$ \\
\hline $\mathrm{TNF} \alpha$ & $30.99 \pm$ & $29.24 \pm$ & $16.84 \pm$ & 0.270 \\
$(\mathrm{ng} / \mathrm{ml})$ & 6.48 & 8.35 & 0.08 & \\
& & & & \\
$\mathrm{IL}-6$ & $18.31 \pm$ & $14.48 \pm$ & $16.98 \pm$ & 0.052 \\
$(\mathrm{ng} / \mathrm{ml})$ & 1.26 & 0.69 & 0.96 & \\
$\mathrm{CIMT}$ & $0.86 \pm$ & $0.70 \pm$ & $0.69 \pm$ & 0.027 \\
$(\mathrm{~mm})$ & 0.06 & 0.84 & 0.02 &
\end{tabular}

Data presented as mean and SD, *one-way ANOVA.

TNFa: Tumour Necrosis Factor- $\alpha$, IL-6: interleukin-6; CIMT: carotid intima-media thickness.

We concluded that there were significant differences in CIMT values among the three groups. The difference of mean measurement of CIMT between the groups was statistically significant (ANOVA, $\mathrm{p}=0.027$ ). Moreover, posthoc analysis tests results were statistically significant; we found that there was a significant difference between the CIMT control groups and the CIMT groups who had received ACE-I or CCB therapy $(\mathrm{p}=0.027$ and $\mathrm{p}=$ 0.018 ). Still, there was no significant difference in the CIMT between the ACE-I and CCB therapy groups $(\mathrm{p}=0.879)$.

The results of the analysis of the TNF- $\alpha$ and IL- 6 obtained $p=0.270$ and 0.052 , respectively. We 
concluded that there were no significant differences in the TNF- $\alpha$ and IL- 6 between the three groups. Based on the assessment, there was a significant difference between the IL- 6 in the control group and the ACE-I group $(\mathrm{p}=0.017)$.

Table 3. Differences in CMIT, TNF- $\alpha$, and IL- 6 among groups

\begin{tabular}{lccc}
\hline & $\begin{array}{c}\text { Control vs. } \\
\text { ACE-I }\end{array}$ & $\begin{array}{c}\text { Control vs. } \\
\text { CCB }\end{array}$ & $\begin{array}{c}\text { ACE-I } \\
\text { vs. } \\
\text { CCB }\end{array}$ \\
\hline TNF- $\alpha$ & $30.99 \mathrm{vs}$ & $30.99 \mathrm{vs}$ & $29.24 \mathrm{vs}$ \\
$(\mathrm{ng} / \mathrm{ml})$ & 29.24 & 16.84 & 16.84 \\
& $\mathrm{p} 0.609$ & $\mathrm{p} 0.111$ & $\mathrm{p} 0.301$ \\
& & & \\
$\mathrm{IL}-6$ & $18.31 \mathrm{vs}$ & $18.31 \mathrm{vs}$ & $14.48 \mathrm{vs}$ \\
$(\mathrm{ng} / \mathrm{ml})$ & 14.48 & 16.98 & 16.98 \\
& $\mathrm{p} 0.017^{*}$ & $\mathrm{p} 0.381$ & $\mathrm{p} 0.301$ \\
$\mathrm{CIMT}$ & $0.86 \mathrm{vs}$ & $0.86 \mathrm{vs}$ & $0,70 \mathrm{vs}$ \\
$(\mathrm{mm})$ & 0.70 & 0.69 & 0.69 \\
& $\mathrm{p} 0.027$ & $\mathrm{p} 0.018$ & $\mathrm{p} 0.879$
\end{tabular}

Post-hoc LSD; * indicated statistically significant; TNFa: Tumour Necrosis Factor- $\alpha$, IL-6: interleukin-6; CIMT: carotid intima-media thickness.

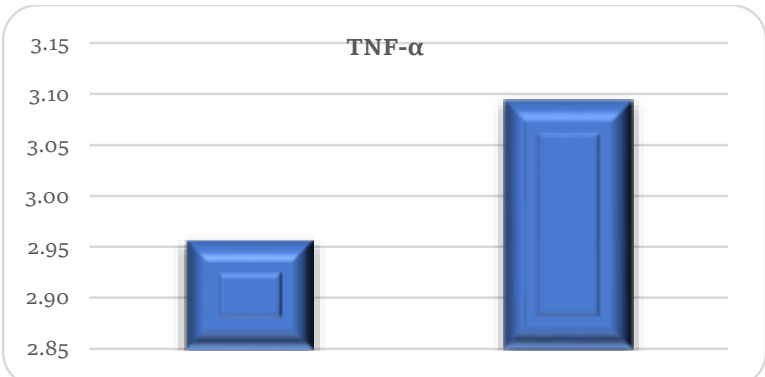

Figure 2. Histogram differences in TNF- $\alpha$ levels with respect to CIMT.

Data presented as mean and SD. TNF $\alpha$ : Tumour Necrosis Factor- $\alpha$, CIMT: carotid intima-media thickness.

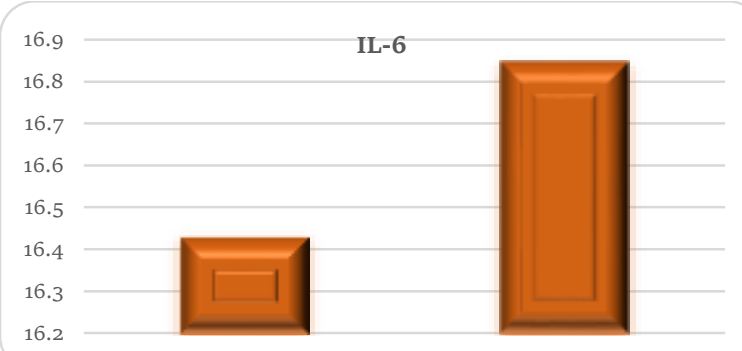

Figure 3. Histogram differences in IL-6 levels with respect to CIMT.

Data presented as mean and SD. IL-6: interleukin-6; CIMT: carotid intima-media thickness.

As described in (Figure 2) and (Figure 3), we could see that the average level of TNF- $\alpha$ and IL6 on thickened CIMT is higher than non-thickened CIMT, but not significant statistically.

Table 4. Difference level of TNF- $\alpha$ and IL- 6 based on CIMT

\begin{tabular}{lccc}
\hline & $\begin{array}{c}\text { Thickened } \\
\text { CIMT }\end{array}$ & Non-thickened CMIT & $P$ \\
\hline $\begin{array}{l}\text { TNF- } \alpha \\
(\mathrm{ng} / \mathrm{ml})\end{array}$ & 2.95 & 3.09 & 0,618 \\
\hline
\end{tabular}

IL-6 (ng/ml) 16.43 16.85 0,808

${ }^{*} T N F \alpha$, Tumour Necrosis Factor- $\alpha$; IL-6, interleukin-6; CIMT, carotid intima-media thickness.

The Differences of BMI, LDL level, TG level, and Systolic blood pressure among groups.

According to previous studies, several factors could influence the CIMT, including BMI, LDL levels, TG levels, and blood pressure. For this reason, we analyzed each variable among groups. There was no difference statistically in term of LDL level, TG level, and blood pressure among groups (Table 5).

Table 5. Difference of BMI, LDL level, TG level, and Systolic blood pressure among groups

\begin{tabular}{lcccc}
\hline Variables & $\begin{array}{c}\text { Control } \\
\text { (n:12) }\end{array}$ & $\begin{array}{c}\text { ACE-I } \\
\text { (n: } 9)\end{array}$ & $\begin{array}{c}\text { CCB } \\
\text { (n:9) }\end{array}$ & $P$ \\
\hline BMI & 29.49 & 26.12 & 30.11 & 0.057 \\
$\left(\mathrm{~kg} / \mathrm{m}^{2}\right)$ & & & & \\
$\mathrm{SBP}$ & 162.25 & 165.0 & 171.1 & 0.660 \\
$(\mathrm{mmHg})$ & & 0 & 1 & \\
& & & & \\
$\mathrm{LDL}$ & 131.83 & 161.2 & 136.8 & 0.176 \\
$(\mathrm{mg} / \mathrm{dl})$ & & 2 & 7 & \\
$\mathrm{TG}$ & 127.08 & 156.6 & 120.4 & 0.183 \\
$(\mathrm{mg} / \mathrm{dl})$ & & 7 & 4 & \\
\hline
\end{tabular}

$B M I$, body mass index; SBP, systolic blood pressure; $L D L$, low density lipoprotein; TG, triglyceride.

On the other hand, there were significant differences in BMI between group 2 and control group $(P=0.046)$ and between group 2 and group 3 $(\mathrm{p}=0.028)$ (Table 6).

Table 6. Difference of BMI among groups

\begin{tabular}{lcccc}
\hline & Control & Control & ACE-I & $P$ \\
vs & Vs & vs & \\
& ACE-I & CCB & CCB & \\
\hline BMI & 29.49 vs & 29.49 vs & 29.49 vs & 0.057 \\
$\left(\mathrm{~kg} / \mathrm{m}^{2}\right)$ & 26.12 & 30.11 & 30.11 & \\
& $\mathrm{p} 0.046$ & $\mathrm{p} 0.702$ & $\mathrm{p} 0.028$ & \\
& &
\end{tabular}

From the CIMT Analysis of the TNF- $\alpha$, IL- 6 , BMI $\left(>25 \mathrm{~kg} / \mathrm{m}^{2}\right.$ and $\left.<25 \mathrm{~kg} / \mathrm{m}^{2}\right)$, TDS ( $>160$ and $<160)$, LDL $(>130$ and $<130)$ and TG $(>150$ and $<150$ ), we found that there was a significant difference in CIMT (Table 7).

Table 7. The Comparison of mean CMIT Thickening based on BMI, LDL level, TG level, and TDS among groups.

\begin{tabular}{|c|c|c|c|}
\hline Group & & $\begin{array}{c}\text { Mean of } \\
\text { CIMT }\end{array}$ & $P$ \\
\hline \multicolumn{4}{|c|}{ BMI $\left(\mathrm{kg} / \mathrm{m}^{2}\right)$} \\
\hline & $>25$ & 078 & \multirow{2}{*}{0.746} \\
\hline & $<25$ & 0.75 & \\
\hline \multicolumn{4}{|c|}{ LDL (mg/dl) } \\
\hline & $>130$ & 0.72 & \multirow{2}{*}{0.258} \\
\hline & $<130$ & 0.79 & \\
\hline \multicolumn{4}{|c|}{ TG (mg/dl) } \\
\hline & $>150$ & 0.76 & \multirow{2}{*}{1.000} \\
\hline & $<150$ & 0.76 & \\
\hline
\end{tabular}


$\mathrm{SBP}(\mathrm{mmHg})$

$>160 \quad 0.77$

$<160 \quad 0.70$

${ }^{*} B M I$, body mass index; $L D L$, Iow density lipoprotein; $T G$, triglyceride, SBP; systolic blood pressure.

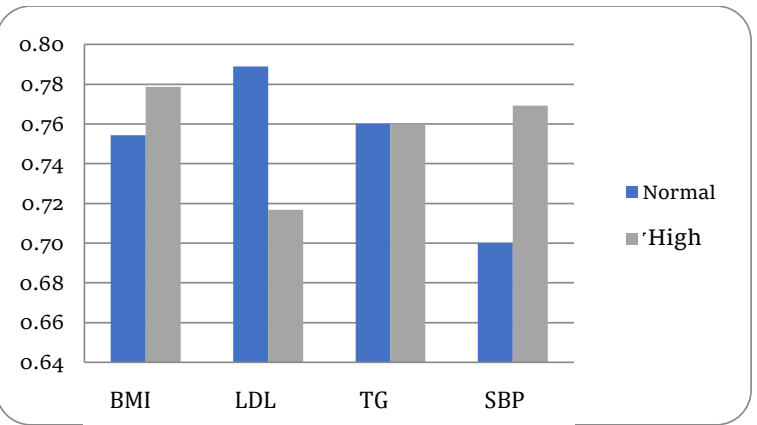

Figure 4. Histogram of CIMT based on BMI, LDL, TG and Systolic Blood Pressure.

BMI, body mass index; $L D L$, low density lipoprotein; $T G$, triglyceride; SBP, systolic blood pressure.

(Table 7) and (Figure 4) showed that the mean of CIMT was thicker on BMI $>25 \mathrm{~kg} / \mathrm{m}^{2}$, as well as at SBP $>160 \mathrm{mgHg}$, but in both of TG groups, the mean of CIMT was not different. Even in the LDL, the CIMT was thicker in LDL $<130 \mathrm{mg} / \mathrm{dl}$. From the test results showed that the $p>0.05$ on all variables, which means there was no significant difference from the CIMT on BMI group (normal and obese), LDL level (normal and above $150 \mathrm{mg} / \mathrm{dl}$ ), TG level (below $130 \mathrm{mg} / \mathrm{dl}$ and above $130 \mathrm{mg} / \mathrm{dl}$ ), and SBP (under $160 \mathrm{mmHg}$ and above $160 \mathrm{mmHg}$ ).

\section{I S C U S S I O N}

\section{The Differences of CIMT in hypertensive patients}

Our study showed, that there was a significant difference between the CIMT of the control group and the hypertensive group who had received therapy (treated groups). We found the lowest CIMT in the group 3 (CIMT of control was $0.86 \pm 0.06(0,60-1.0)$; ACE-I was $0.70 \pm 0.04$ (0.50-0.90); and CCB was 0.69 $\pm 0.02(0.60-0.75) ; \mathrm{p}=0.027)$.

Hypertension is an important risk factor for cardiovascular complications [19], especially stroke.[20] It also has an important complex role in the pathogenesis of atherosclerosis. A continual elevated in blood pressure caused changes in vascular endothelial function, such as increased vascular permeability, decreased endothelial vasodilators, and increased adherence of leukocytes on the surface of the endothelium to the accumulation of macrophages in the intima layer. $[8,9,21]$

Hypertension also increases vascular smooth muscle cell (VSMC) proliferation. On the other hand, inflammation and endothelial dysfunction also play a critical role in the pathogenesis of hypertension. ${ }^{[22]}$ systolic hypertension isolated with elevated pulse pressure is an indication of blood vessel stiffness, that can be considered as a marker of atherosclerosis. Several studies have shown a correlation between hypertension and CIMT thickness and blood vessel stiffness. $[11,13,17]$

The important role of CIMT as a marker of atherosclerosis has been widely demonstrated in various clinical studies. In line with Shetty et al, which examined 100 patients with a history of coronary artery disease. They found that CIMT patients with a history of coronary artery disease had thicker CIMT compared to the control group (23). In another study, De Groot et al., found that CIMT can be an accurate predictor of atherosclerosis progression in familial hypercholesterolemia patients (10). Ainsworth et al., who conducted a study of 38 patients with carotid artery stenosis, found that B-mode ultrasonography of the carotid artery was very useful for assessing the therapeutic response in patients with atherosclerosis (24).

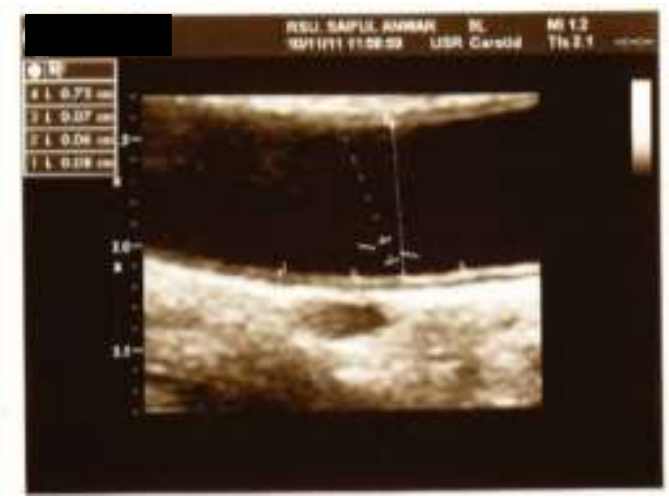

Figure 5. Carotid artery CIMT Examination Using B-Mode Ultrasonography

From meta-analysis results of 8 studies, Wang et al, found that eight studies involving 3329 patients with coronary heart disease due to diabetes, who received antihypertensive therapy with ACE-I, $\alpha$-blockers, or CCB compared to placebo could reduce CIMT thickening of $7 \mu \mathrm{m} /$ year $(p<0.01)^{(25)}$. Also, 9 other studies involving 4564 hypertensive patients who received ACE-I, CCB, and ARB therapy compared with a diuretic or $\beta$-blocker therapy, the effect of reducing blood pressure can cause a reduction in CIMT thickness of $3 \mu \mathrm{m} /$ year $(p<0.03)$. Other study also found the superiority of CCB in reducing CIMT thickness of $5 \mu \mathrm{m} /$ year in 5 studies involving 3619 patients. This reduction of CIMT thickness was related to changes in lumen diameter, but that was 
not associated with differences in achieved blood pressure.[17]

Our study showed that patients with the amlodipine treatment had the lowest CIMT thickness, which is $0.69 \mathrm{~mm}$. Lai et al., reported the same result. In their study of hypertensive rats, Lai et al,, investigated the effects of amlodipine on vascular smooth muscle proliferation(26). Amlodipine can inhibit DNA synthesis and VSMC proliferation by evaluating the growth factor expression impact, phenotype changes, and vascular smooth muscle cell (VSMC) proliferation in hypertensive rats. Amlodipine can inhibit the expression of plateletderived growth factor (PDGF), transforming growth factor $\beta 1$ (TGF- $\beta 1$ ), and basic fibroblast growth factor (bFGF), also mRNAs in vascular smooth muscle cells of hypertensive rats. Amlodipine inhibits the marker expression of osteopontin synthesis phenotypes and Gla mRNAs matrix, which shows the process of inhibiting VSMC growth and changing contractile phenotypes into synthetic phenotypes. In their study, Lai et al.,[26] investigated the effect of amlodipine on the overgrowth of VSMC culture in hypertensive rats. Therefore, it can be assumed that the antiproliferative effect of amlodipine is not associated with a decrease in blood pressure.

Stevo Julius et al. [27] in the VALUE (Valsartan Antihypertensive Long-Term Use Evaluation) trial examined 15.245 patients with high-risk hypertension treated with valsartan or amlodipine. They evaluated on 7080 patients to use one kind of antihypertensive drug within six months. The result is no significant differences found between various cardiac endpoints, stroke, myocardial infarction, and death from any cause. However, they found that the incidence of heart failure was lower in the valsartan therapy group (hazard ratios: $0.63, p=0.004$, and $0.78, \mathrm{p}=.045$, respectively). The duration of monotherapy in

each group increased the relative risk of heart failure, and new-onset diabetes (odds ratios: $0.78, \mathrm{p}$ $=0.012$, and $0.82, \mathrm{p}=0.034$; respectively).

The levels of intracellular free calcium ions partially influenced the growth of VSMC, which VOCC (Voltage operated calcium channel) plays a vital role in the homeostasis of calcium ions in intracellular VSMC. CCB is bound to the voltagesensitive calcium channel, causing a decrease of an influx in extracellular calcium ion through sarcolemma, decreasing calcium levels in the cytosol, and suppressing the mechanism of contraction initiation from VSMC. Amlodipine is lipophilic, which belongs to the long-acting dihydropyridine CCB group, and shows slow association and dissociation with the calcium channel receptor.[28]

In the Prospective Randomized Evaluation of the Vascular Effects of Norvasc Trial (PREVENT) study[29], which was a multicentre, randomized, double-blind placebo-control studies to test whether amlodipine can postpone the progression of early coronary atherosclerosis in 825 patients with coronary heart disease that has been proven angiographically or not. Based on the observation of 36 months of therapy, there was no change angiography on the diameter of the segment acoroners who had experienced stenosis of $30 \%$. The studies of B-mode ultrasonography were conducted to assess whether amlodipine can inhibit the process of atherosclerosis or not. Amlodipine is known to have a significant effect in slowing the progression of carotid artery atherosclerosis within 36 months of therapy. That is, the placebo group had a thick CIMT increasing of $0.033 \mathrm{~mm}$, whereas in the amlodipine group had $0.0126 \mathrm{~mm}(p=0.007)$.

In the third generation of L-Type CCB, amlodipine has been proved to have beneficial effects for the treatment of heart and blood vessel disease. Detry et al.[30] conducted a CAPE trial, which resulting amlodipine could reduce the incidence of ischemia in patients with coronary heart disease. In the Coronary Angioplasty Amlodipine Restenosis (CAPARES Study)

study, [31] amlodipine has been proved to reduce the need for revascularization in patients with stable angina.

Beyond its ability to cause vasodilation through inhibition of calcium channels, we proved that longterm CCB to have a beneficial effect in patients of coronary heart disease regardless of its impact in lowering blood pressure, which underline this effect. It was assumed to be associated with the biochemical characteristics of amlodipine, which the aminoethoxy function connected to the dihydropyridine ring, which would be in an electrically charged ion condition at a physiological-pH. This positive electrical charge which caused strong electrostatic interactions between amlodipine and phospholipids in cell membranes. Amlodipine's affinity to the plasma membrane would be maintained even in proatherogenic condition§such 
as increased levels of cholesterol in the membrane. Also, with its strong affinity and supported by its lipophilic, amlodipine can inhibit the modified LDL aggregation, which is a crucial step in the process of foam cells mediated by oxidized and negatively charged lipids. The atheroprotective factor of amlodipine is not shared by other classes of antihypertensive drugs, because it does not have biochemical characteristics as amlodipine had. [28]

The dihydropyridine ring structure of amlodipine is at the same depth as the sterol core of cholesterol. In this position, amlodipine can reverse the effects of cholesterol on membrane structure and function. Precisely, amlodipine can affect the ability of cholesterol to increase the surface area of membranes and bonding into a similar domain crystal, as illustrated in the native or oxidized cholesterol model in atherosclerotic cases. ${ }^{[32]}$

Amlodipine has an antioxidant effect through its ability to reduce oxidative modification of LDL and lipid membranes. Oxidative modification of LDL and lipid membranes causes the formation of foam cells, endothelial dysfunction, and destructive inflammatory processes associated with atherosclerosis. ${ }^{[33]}$ Various in vitro and in vivo studies showed that CCB with high lipophilic inhibits oxidative damage to lipids related to cell membranes and lipoprotein particles. [34,35]

$$
\text { Under experimentally controlled }
$$

conditions, amlodipine can hinder the formation of lipid peroxidase at a concentration of $10 \mathrm{nmol} / \mathrm{L}$, without the affection of calcium channel modulation.[36] The antioxidant activity of amlodipine is an effect of the highly lipophilic of amlodipine and its chemical structure, which allows proton donor and resembles a stabilization mechanism that reduces free radical reactions. [37] By inserting into the location in the membrane near a conjugated double bond, the highly lipophilic CCB can donate protons to the lipid peroxidase molecule, thus inhibiting the process of peroxidation. Dihydropyridine (DHP) rings can stabilize free unpaired electrons in drug molecules. The reactions that describe the antioxidant effect of dihydropyridine CCB are defined as follows: (LOO• represents the lipid peroxidase molecule): $\mathrm{LOO} \bullet+\mathrm{DHP} \rightarrow \mathrm{LOO}+\mathrm{DHP} \bullet$

The antioxidant effect of amlodipine has also been observed in vivo in various experiments to animals, including primates, which show a highly significant antiatherogenic effect of this dihydropyridine group. ${ }^{[38]}$ Including lacidipine, a proven substance, in preclinical study models can affect the thickness of the media intima and the amount of plaque. ${ }^{[11]}$

From the summary of the one-way ANOVA of each variable that can affect CIMT, we concluded that there were no significant differences among each group in TNF- $\alpha$, IL-6, LDL, Triglyceride, BMI and systolic blood pressure ( $P: 0,270 ; P: 0,052 ; P$ : $0,176 ; P$ : 0,183; $P: 0,057 ; P: 0,660)$. After the posthoc analysis, there were only two variables that were significantly different, which were IL-6 between the group with ACE-I therapy, and the group that had not received treatment was $P=$ 0.017 and BMI between the group with ACE-I therapy and the group that had not received therapy was $P=0.045$.

\section{CIMT based on Levels of TNF- $\alpha$ and IL- 6}

In this study, the results of hypertensive patients who received therapy had lower levels of inflammatory markers compared to patients who had not received treatment, (TNF- $\alpha$ of the control group was $30.99 \pm 6.48$; ACE-I was $29.24 \pm 8.35$; CCB was $16.84 \pm 0.88)$ although after statistical tests, no significant difference was found (TNF- $\alpha$ 0.618, IL-6 P= 0.08).

Inflammation demonstrated a critical role in the development of atherosclerosis. ${ }^{[39,40]}$ Hypertension is a factor that influences the high level of cytokines in the process of atherogenesis. ${ }^{[41]}$ Chae et al., in a crosssectional study of 508 healthy men examining the relationship of hypertension and atherosclerosis through proinflammatory effects, found that increased SBP, pulse pressure, and MAP were significantly associated with sICAM-1 and IL-6.[42] High levels of proinflammatory cytokines such as IL-6, supported the evidence for the role of proinflammatory cytokines in the process of atherogenesis. ${ }^{[43]}$ Even before the myocardial infarction occurred.

VSMC stimulation by angiotensinII (ANGII), which is a blood pressure regulator, caused inflammatory activation due to the expression and release of IL-6. IL-6 also caused vascular smooth muscle cell proliferation, which is an early sign of atherosclerosis due to hypertension. Hypertension can cause pro-inflammatory effects through increased oxidative stress.[44] In experimental with animal studies with hypertension induced by AngII,[45], it found an increased superoxide anion in blood vessels, 
as well as inflammatory responses, which is aortic infiltration by monocytes and macrophages.

Ang-II has a critical role in the process of atherosclerosis through a mechanism involved either dependent or independent on changes in blood pressure. Ang-II roles were not only increasing IL-6 expression but also stimulates the expression of sICAM and infiltration of blood vessels by monocytes and macrophages, which can be inhibited by drugs, which is ACE-Inhibitor or AngiotensinII receptor blockers (ARBs). ${ }^{[39,46]}$

TNF- $\alpha$ is a protein that was mainly synthesized by monocytes and macrophages, which plays a vital role in the initiation of immune system activation, sugar, and fat metabolism. TNF- $\alpha$ secretion increases significantly in the monocytes in peripheral blood in patients with high blood pressure after stimulation with lipopolysaccharides. Activated monocytes in hypertensive patients can cause hypertension. TNF- $\alpha$ can trigger insulin resistance and is known to increase its levels in obese patients, which is a condition closely related to hypertension. $[6,47]$

IL-6 is a pleiotropic cytokine produced by various types of cells and works on various types of tissues and cells. In healthy organisms, IL-6 is excreted at low levels and maintained at this level by a complex regulatory network involving corticosteroids, catecholamines, and hormones on secondary sex characteristics. IL-6 gene expressions, especially in monocytes and macrophages, are quickly triggered by viruses and bacterial endotoxins also inflammatory cytokines such as IL-1 and TNF- $\alpha$, PDGF (platelet-derived growth factor) and interferon in response to infections, trauma, and other stressful conditions. IL-6 promoter acts as a biosensor that is sensitive to environmental stress and contains a highly regulated control region that is bound to trigger proteins causing transcription factors related to pro-inflammatory or proliferation conditions, such as Nuclear Factor-kß (NF-kß), C/EBPß (CCAAT enhancer-binding protein), activator protein-1 (AP 1) and corticosteroids.[47] IL-6 is also produced by adipose tissue in response to adiposity cytokines, which explain the relationship between obesity and chronic inflammation as a potential trigger of various cardiovascular diseases and metabolism.[48]

During acute inflammation, IL-6 expression through NF-kß induces the secretion of acute-phase proteins from the liver. Therefore, there will be an increase in the expression of adhesion molecules and secretions from various chemoattractant factor also IL-6 activation may contribute to neutrophil recruitment into the affected tissue by endothelial cell activation. ${ }^{[49]}$ Inactive fibroblasts (fibrocytes) are a part of the inflammatory milieu that produces MMS due to the stimulation of IL- 6 to degrade the extracellular matrix.[50] Furthermore, IL-6 also regulates temporary changes in the pattern of leukocyte recruitment that was initially dominated by neutrophils to monocyte dominance, thereby facilitating the changes in innate immune response become adaptive responsiveness. [51]

Additionally, in endothelial cells, IL- 6 has been demonstrated to stimulate the proliferation and migration of circulating endothelial progenitor cells ${ }^{[52]}$ that emphasizing the proangiogenic properties of IL-6 ultimately. Also, IL-6 is involved in the migration of VSMC through mediating the effects of vascular endothelial growth factor (VEGF) and TNF- $\alpha .{ }^{[53]}$ Further, IL-6 can also stimulate VSMC proliferation with or without passing through PDGF (Platelet-derived growth factor).[54]

The role of the Renin-angiotensin-system (RAS) is an important factor in blood pressure regulation since the kidney isolated renin. Goldblatt et al. [55] demonstrated the induction of hypertension by renal artery occlusion, and then it was found that renin as being responsible for this phenomenon. ANGII is a potent vasoconstrictor that causes aldosterone excretion due to sodium and water retention in the kidney. Thus, acute ANGII secretion prevents fatal hypotension. Chronic activation of ANGII can increase blood pressure and volume overload, thus causing mechanical stress on the walls of the arteries.[56] Activation of tissue-specific RAS also increases systemic RAS, which will cause an increase in vascular ROS production.[57] ANGII affects blood pressure through various mechanisms. It also has inflammatory, remodeling, and thrombotic effects in blood vessels due to the induction of pro-inflammatory cytokines IL-6 or TNF- $\alpha{ }^{[58]}$ also various chemokines and growth factors in VSMC.[59] ANGII's fibrogenic action exacerbates all of these factors through the induction of MMPI and PAI$1 .{ }^{[60]}$

Based on our investigation, although proinflammatory cytokine levels were higher in the thickened CIMT, there were no significant differences ( $p=0.270$ for TNF- $\alpha$ and $p=0.052$ for IL-6). Al Daghri et al. [61] examined pro-inflammatory cytokine leyels in 
male and female adults in Saudi Arabia, they found a intracellular cholesterol through the mechanism of significant relationship between hypertension and Sterol Regulatory Element-Binding Proteins inflammatory markers in women, but they could not (SREBPs). On the contrary, modified forms of LDL, find in men. Then, we concluded that there was the such as acetylated LDL and oxidized LDL, are quickly effect of gender differences in the relationship between captured by macrophages through Scavenger inflammatory markers with insulin resistance and Receptors (SRs), causing cholesterol accumulation hypertension, which can be caused by different fat and foam cell formation because the oxidized LDL distribution due to gender differences.

\section{Association between BMI and CIMT}

Obesity showed an association with increased cardiovascular risk. ${ }^{[62]}$ In the U.S. Diabetes Prevention Program, the incidence of diabetes was reduced by $58 \%$, with an average weight loss of $5.8 \mathrm{~kg}$ through interventions for physical activity and dietary patterns change. ${ }^{[63]}$ It is unclear whether the other risk factors worsening mediated the relationship between obesity and cardiovascular risks, such as insulin resistance, components of metabolic syndrome, inactivity, or the proinflammatory consequences of obesity.[64,65] We assumed that there might be many mechanisms by which obesity affects the cardiovascular risk that had not been revealed. ${ }^{[62]}$ In this present study, patients with a higher BMI had thicker CIMT compared to patients with a lower BMI. However, after statistical analysis, there were no significant differences $(P=0.746)$.

\section{CIMT based on Level of LDL and Triglycerides}

The result of this present study is no significant differences found in CIMT between hypertensive patients with high LDL and triglyceride levels and low LDL and triglyceride levels ( $P=0.285$ and $P=1.00$ ). The result is similar to Kandil et al.[66], who examined the relationship of inflammatory markers with CIMT in obese children and non-obese in Egypt, which did not show a significant relationship of the total cholesterol, triglyceride, and LDL levels with CIMT. Oren and Thomas's observation[67] also found no significant relationship between lipids and CIMT, except HDL-C levels. However, Li et al.[68] reported a consistent relationship between LDL-C as a valuable predictor of CIMT in the young adult population.

The oxidation of LDL is a crucial step in the process of atherogenesis. However, the mechanism of LDL oxidation is still not fully understood. Cholesterol uptake by LDL receptors does not allow cholesterol accumulation in macrophages because LDL receptors are downregulated by increased

The LDL oxidation hypothesis states the LDL oxidation process is the initial step in the process of atherosclerosis. ${ }^{[70]}$ This hypothesis is supported by the evidence shows that oxidized LDL can trigger foam cells in in vitro studies. We can find oxidized LDL over in vivo. It has a variety of proatherogenic potentials such as stimulation of endothelial cells and monocytes that causing increased of proinflammatory cytokines, chemokines and adhesion molecules, monocyte and macrophage stimulation which will increase tissue factors, matrix metalloproteinases, and scavenger receptors, which cause foam cell formation by macrophages and the development of atherosclerotic lesions.[70] The process of LDL oxidation does not occur in the circulation, but in the walls of blood vessels because serum lipoproteins are protected from oxidation by its retaining mechanism. For its transport, LDL contains a lot of alpha-tocopherol, an antioxidant vitamin. [71] LDL can have an exposure to various oxidants from cells in the subendothelial layers of the arterial wall. LDL oxidation can transfer via a nonenzymatic pathway, which is by the transition of metal ions, hemin, and the other kind of catalysts. Several theories explained the oxidation of LDL through an enzymatic system in the arterial wall. LDL particles undergo oxidative modification via incubation in macrophage cells, endothelial cells, and smooth muscle cells.[72]

Referring to this present study, we found that higher LDL levels in the CIMT group were $<0.7$, this could be due to false positives in the sample because of the lack of patient's fasting and eating patterns assessment so that the patient's serum became more turbid, which interfered the readings. The method of examination also determines the results of lipid profile testing. [73]

\section{CIMT and systolic blood pressure}

Hypertension is known to increase shear stress, which induces endothelial dysfunction, which is an essential step in the process of atherosclerosis.[74,21] endothelial dysfunctions gwill 
induce various inflammatory cytokines and adhesion molecules, which mediate monocyte migration and oxidized LDL to the tunica media of blood vessels, which is the initial step to form foam cells. By the accumulation of foam cells in the tunica intima, numerous immunological responses will occur, and inflammatory cytokines will be released, as well as chemokines and metalloproteinases that will cause atherosclerosis development. ${ }^{[8,75]}$

Lakka et al. in a 4-year cohort study of 1229 adult men aged 42-60 years, found that SBP and pulse pressure have a strong correlation with the process of atherosclerosis as measured by CIMT thickening. [44]

According to this present study's observation, the blood pressure of patients with a SBP of $>160$ had a thicker CIMT compared to patients with the SBP of $<160$ (0.70 vs. 0.77 ). Still, when conducting the statistical analysis, there was no significant difference between both groups $(\mathrm{p}=$ 0.455).

Bots et al.[76] in a meta-analysis stated that they needed some 468 patients in each group for a parallel clinical study to assess changes in CIMT with the effect of $30 \%$ for two years or 30 patients in each group for the effect of $100 \%$ with three years observation length.

The CAMELOT study[77], examined the effect of antihypertensive drugs (amlodipine vs. enalapril) in patients with a blood pressure of $<140 / 90 \mathrm{mmHg}$ with a history of Coronary Artery Diseases (CAD) in Cardiovascular Disease (CVD) risk assessed by IVUS (intravenous ultrasonography) testing to compare the anti-atherosclerotic effects of the two drugs. The results of the CAMELOT study showed no

significant difference between amlodipine and enalapril in CVD outcomes, but the progression of atherosclerosis assessed by IVUS was lower in the amlodipine group.

The limitation of this study was related to the research method. Limited therapeutic time and the difficulty of determining a starting point of the study profoundly affected the results of the investigation. Besides, a minimal number of samples also affect the results. Thus, the research needed a longer observation time and a larger number of samples by looking at the effects of pre- and post-therapy.

\section{O N C L US I O N}

We concluded that there was a significant difference in CIMT between hypertensive patients who have not received therapy, hypertensive patients with ACE-I treatment and hypertensive patients with CCB therapy. The lowest CIMT thickness found in groups with CCB therapy. However, there was not enough evidence to say there were differences between the three groups on the score changes of TNF- $\alpha$, IL-6, BMI, LDL, TG, and TDS. Thus, we assumed that the differences in the thickness of CIMT of the three groups were not dependent on TNF- $\alpha$, IL-6, BMI, TG, LDL, or systolic blood pressure. It is in line with studies related to amlodipine, which has a robust lipophilic effect and could do protons donor, thus inhibiting oxidative stress due to lipid peroxidation. Moreover, because this study was a cross-sectional study, we could not conclude the cause-effect or relationship between parameters.

We suggested other researchers conduct similar research with a cohort design and a larger sample size also longer therapy duration to obtain a valid sample and be able to observe the effects of pre- and posttherapy. It is essential to consider the role of various other risk factors in analyzing the relationship of CIMT with hypertension, such as gender, age, such as obesity, dyslipidemia, hypertriglyceridemia, and high markers of inflammation.

\section{RE F E R E N C E S}

1. Watson RE, DiPette DJ, Sarikonda VK, Opara OC. Experimental Animal Models of Hypertension. In: Joseph IL, Black HR, Goodfriend TR, Sowers JR, Weber AB, editors. Hypertension Primer: The Essentials of High Blood Pressure Editors. Iowa: Lippincot Williams \& Wilkins Inc. 2003; 3: (2-124). [PMID:20409957.https://doi.org/10.1016/j.jash.2009.02.003.]

2. Boos CJ and Lip G.Y.H. "Is Hypertension an Inflammatory Process?" Current Pharmaceutical Design. 2006; 12: 1623. [PMID: 16729874.

https://doi.org/10.2174/138161206776843313]

3. Jian-Jun L. Inflammation in hypertension: Primary evidence. Chinese medical journal. 2006; 119.1215-21. [PMID: 16863616. https://doi.org/10.1097/00029330-200607020-00016.]

4. Hilgers K. Monocytes/Macrophages in Hypertension. J Hypertension. 2002; 20: 593-596 [PMID: 11910288. https://doi.org/10.1097/00004872-200204000-00010]

5. Montecucco F, Pende A, Quercioli A, Mach F. Inflammation in the pathophysiology of essential hypertension. Journal of Nephrology. 2011 Jan-Feb; 24(1):23-34.[PMID:20437401. https://doi.org/10.5301/in.2010.4729]

6. Bautista L, Vera LM, Arenas IA, Gamarra G. Independent Association between Inflammatory Markers (C Reactive Protein, Interleukin-6, and TNF- $\alpha$ ) and Essential Hypertension. Journal of Human Hypertension. 2005; 19:149-154. [PMID:15361891. https://doi.org/10.1038/sj.jhh.1001785]

7. Kim KI, Lee JH, Chang HJ, et al. Association between Blood Pressure Variability and Inflammatory Marker in Hypertensive Patients. $\begin{array}{lllll}\text { Circ J. 2008; } 72 & \text { (2): 293-8 [PMID: } 18219169\end{array}$ https://doi.org/10.1253/circj.72.293]

8. Libby $\mathrm{P}$, Ridker PM, and Maseri A. Inflammation, and Atherosclerosis. Circulation. 2002; 26; 420 (6917):868-74 [PMID: 11877368. 10.1161/hc0902.104353] 
9. Libby P. Inflammation in atherosclerosis. Nature. 2002. 420(868872).[PMID:12490960. https://doi.org/10.1038/nature01323]

10. Groot ED, Hovingh GK, Wiegman A, Duriez P, Smit AJ, Fruchart JC, et al. Measurement of Arterial Wall Thickness as a Surrogate Marker for Atherosclerosis. Circulation. 2004; 109(23 Suppl 1): III33-8. [PMID:

15198964 https://doi.org/10.1161/01.CIR.0000131516.65699.ba]

11. Zanchetti A, Hennig M, Hollweck R, Bond G, Tang R, Cuspidi C, et al. Baseline Values but Not Treatment-Induced Changes in Carotid Intima-Media Thickness Predict Incident Cardiovascular Events in Treated Hypertensive Patients Findings in the European Lacidipine Study on Atherosclerosis (ELSA). Circulation. 2009 120(12):1084-90.[PMID:19738145

https://doi.org/10.1161/CIRCULATIONAHA.108.77311]

12. Pignoli P, Tremoli E, Poli A, Oreste P, Paoletti R. Intimal Plus Medial Thickness of The Arterial Wall: A Direct Measurement with Ultrasound Imaging. Circulation .1986; 74(6):1399406.[PMID:3536154. https://doi.org/10.1161/01.cir.74.6.1399]

13. Okazaki S, Furukado S, Abe Y, Tanaka M, Miwa K, Yamagami H, et al. Association of Inflammatory Markers and Carotid IntimaMedia Thickness with the Risk of Cardiovascular Events in HighRisk Patients. Cerebrovasc Dis.2010;30(2):1807.[PMID:20588013. https://doi.org/10.1159/000317106]

14. Stein JS, Korcarz CE, Hurst RT, et al. Use of Carotid Ultrasound to Identify Subclinical Vascular Disease and Evaluate Cardiovascular Disease Risk: a Consensus Statement from the

American Society of Echocardiography Carotid Intima-Media Thickness Task Force. J Am Soc Echocardiography. 2008; 91: 93- 111. [PMID:18261694. https://doi.org/10.1016/i.echo.2007.11.011]

15. Mancini, GB, Henry, GC, Macaya, C, et al. Angiotensin-Converting Enzyme Inhibition with Quinapril Improves Endothelial Vasomotor Dysfunction in Patients with Coronary Artery Disease: The TREND (Trial on Reversing Endothelial Dysfunction) Study. Circulation. 1996; 94(3):258-65. [PMID: 8759064. https://doi.org/10.1161/01.CIR.94.3.258]

16. Staessen, JA, Wang JG, and Thijs L. Cardiovascular Protection and Blood Pressure Reduction: A Meta-Analysis. Lancet. 2001; 20:358(9290):1305-15.

https://doi.org/10.1016/S0140-6736(01)06411-X]

17. Wang JG, Staessen JA, Li Y, et al. Carotid Intima-Media Thickness, and Antihypertensive Treatment. Stroke. 2006; 37(7):1933-40 [PMID:16763185.

https://doi.org/10.1161/01.STR.0000227223.90239.13]

18. Plank MJ, DJN Wall, and T David. Atherosclerosis and Calcium Signalling in Endothelial Cells. Progress in Biophysics and Molecular Biology. 2006; 91(3):287-313 [PMID:16171849. https://doi.org/10.1016/j.pbiomolbio.2005.07.005]

19. Stamler R, Ford CE, and Stamler J. Why Do Lean Hypertensives Have Higher Mortality Rates Than Other Hypertensives? Findings of the Hypertension Detection and Follow-up Program. North Western University Medical School. 1991; 17(4):553-64 [PMID: 2013482. DOI: https://doi.org/10.1161/01.hyp.17.4.553]

20. Lawes CMM, Bennett DA, Feigin VL, Rodgers A. Blood Pressure and Stroke: An Overview of Published Reviews. Stroke. 2004; 35:776-785 [PMID: 15053002 . https://doi.org/10.1161/01.STR.0000116869.64771.5A]

21. Christopher G and Joseph W. Atherosclerosis: The Road Ahead. Cell. 2001; 104(4):503-16. [PMID: 11239408. https://doi.org/10.1016/s0092-8674(01)00238-0]

22. Spieker L, Noll G \& Ruschitzka F, et al. Working under pressure: The vascular endothelium in arterial hypertension. Journal of human hypertension. 2002;14.617-30. [PMID: 11095155. https://doi.org/10.1038/sj.jhh.1001012]

23. Shetty S, George P, Venkatesha B \& Alva, Jayaprakash. A Study to Correlate Carotid Intima Thickness by B-Mode Ultrasonography in Patients Documented with Coronary Artery Disease. Heart views: the official journal of the Gulf Heart Association. 2011; 12(4): 157-160. [PMID: 22574241. https://doi.org/10.4103/1995-705X.90902]
24. Ainsworth, Craig \& Blake, Christopher \& Tamayo, Arturo \& Beletsky, Vadim \& Fenster, Aaron \& Spence, J. David. 3D Ultrasound Measurement of Change in Carotid Plaque Volume A Tool for Rapid Evaluation of New Therapies. Stroke. 2005; a Journal of Cerebral Circulation. [PMID: 1608185736. https://doi.org/10.1161/01.STR.0000178543.19433.20]

25. Wang JG, Staessen JA, Li Y, et al. Carotid Intima-Media Thickness and Antihypertensive Treatment A Meta-Analysis of Randomized Controlled Trials. Stroke. 2006; 37(7):1933-40.[PMID:16763185. https://doi.org/10.1161/01.STR.0000227223.90239.13]

26. Lai YM, Fukuda N, Su JZ, et al. Novel Mechanisms of the Antiproliferative Effects of Amlodipine in Vascular Smooth Muscle Cells from Spontaneously Hypertensive Rats. Hypertens Res. 2002; 25(1):109-15 [PMID: $11924715 . \quad \underline{\text { https://doi.org/ }}$ 10.1291/hypres.25.109]

27. Julius S, Weber MA, Kjeldsen SE, et al. The Valsartan Antihypertensive Long-Term Use Evaluation (VALUE) Trial Outcomes in Patients Receiving Monotherapy. Hypertension. 2006; 48(3):38591.[PMID:16864741. https://doi.org/10.1161/01.HYP.0000236119.96301.f2]

28. Mason, RP, Marche P, and Hintze TH. Novel Vascular Biology of Third-Generation L-Type Calcium Channel Antagonists Ancillary Actions of Amlodipine. Arterioscler Thromb Vasc Biol. 2003; 23(12):2155-63 [PMID: 14512371. https://doi.org/10.1161/01.ATV.0000097770.66965.2A]

29. Pitt B, Byington RP, Furberg CD, et al. Effect of Amlodipine on the Progression of Atherosclerosis and the Occurrence of Clinical Events. Circulation 2000; 102(13):1503-10. [PMID: 11004140. https://doi.org/10.1161/01.CIR.102.13.1503]

30. Detry J. Amlodipine and the Total Ischemic Burden: Circadian Anti Ischemia Program in Europe (CAPE) Trial-Methodology, Safety, and Toleration. The Steering Committee Members and All of the Investigators. Cardiology. 1994; 85 Suppl 2:24-30. [PMID: 7736484. https://doi.org/10.1159/000177044]

31. Jørgensen B, Simonsen S, Endresen K et al. Restenosis and Clinical Outcome in Patients Treated with Amlodipine After Angioplasty: Results from the Coronary AngioPlasty Amlodipine REStenosis Study (CAPARES). JACC 2000;35(3):592-9 [PMID:10716459.https://doi.org/10.1016/S07351097(99)00599-9]

32. Tulenko TN, Chen M, Mason PE, and Mason RP. Physical Effects of Cholesterol on Arterial Smooth Muscle Membranes: Evidence of Immiscible Cholesterol Domains and Alterations in Bilayer Width during Atherogenesis. Journal of Lipid Research. 1998; 39(5):94756 [PMID: 9610760]

33. Witztum J. The Oxidation Hypothesis of Atherosclerosis. Lancet.1994;344(8925):793-5.[PMID:7916078. https://doi.org/10.1016/s0140-6736(94)92346-9]

34. Mason R. Mechanisms of Plaque Stabilization for the Dihydropyridine Calcium Channel Blocker Amlodipine: Review of the Evidence. Atherosclerosis. 2002; 165(2):1919.[PMID:12417269.

https://doi.org/10.1016/S0021-9150(01)00729-8]

35. Kramsch, D. Limits of Lipid-Lowering Therapy: The Potential Benefits of Amlodipine as an Antiatherosclerotic Agent. International Journal of Cardiology. 1997; 62 Suppl 2.S11924.[PMID: 7783112. $\quad$ https://doi.org/10.1016/S01675273(97)00249-0]

36. Chen L, Haught WH, Yang B, et al. Preservation of Endogenous Antioxidant Activity and Inhibition of Lipid Peroxidation as Common Mechanisms Of Antiatherosclerotic Effects Of Vitamin E, Lovastatin And Amlodipine. J Am Coll Cardiol. 1997; 30(2):56975.[PMID:9247534. 1097(97)00158-7] https://doi.org/10.1016/S0735-

37. Mason RP, Walter MF, Trumbore MW, Olmstead EG Jr, Mason PE. Membrane Antioxidant Effects Of The Charged Dihydropyridine Calcium Antagonist Amlodipine. J Mol Cell Cardiol. 1999; 
31(1):275-81.

10072734. https://doi.org/10.1006/imcc.1998.0867]

38. Henry P. Antiperoxidative Actions of Calcium Antagonists and Atherogenesis. J Cardiovasc Pharmacol. 1991; 18: p. S6-S10. [PMID: 1723459]

39. Fan $J$ and Watanabe T. Inflammatory Reactions in the Pathogenesis of Atherosclerosis. J Atheroscler Thromb. 2003;10(2):63-71.[PMID:12740479. https://doi.org/10.5551/jat.10.63]

40. Hansson GK, Libby P, Schönbeck U, Yan ZQ. Innate and Adaptive Immunity in the Pathogenesis of Atherosclerosis. Circ Res. 2002; 91(4):281-91. [PMID: https://doi.org/10.1161/01.res.0000029784.15893.10]

41. Bautista L. Inflammation, Endothelial Dysfunction, and the Risk of High Blood Pressure: Epidemiologic and Biological Evidence. Journal of Human Hypertension. 2003; 17(4):223-30.[PMID:12692566. https://doi.org/10.1038/sj.jhh.1001537]

42. Chae CU, et al. Blood Pressure, and Inflammation in Apparently Healthy Men. Hypertension. 2001. 38: p. 399403.[PMID:11566912. https://doi.org/10.1161/01.HYP.38.3.399]

43. Gorelick PB. Stroke Prevention Therapy beyond Antithrombotics: Unifying Mechanisms in Ischemic Stroke Pathogenesis and Implications for Therapy. Stroke 2002; 33(3):86275.[PMID:11872916. https://doi.org/10.1161/hs0302.103657]

44. Lakka TA, Salonen R, Kaplan GA, Salonen JT. Blood Pressure and the Progression of Carotid Atherosclerosis in Middle-Aged Men. Hypertension. 1999; 34(1):51-6 $\quad$ [PMID: 10406823. https://doi.org/10.1161/01.hyp.34.1.51]

45. Schieffer B, M Luchtefeld, and S Braun. Role Of NAD(P)H Oxidase In Angiotensin II-Induced JAK/ STAT Signalling And Cytokine Induction. Circ Res. 2000; 87(12):1195-201. [PMID:11110778. https://doi.org/10.1161/01.res.87.12.1195]

46. Schieffer B, Schieffer E, Hilfiker-Kleiner D, et al. Expression of Angiotensin II and Interleukin 6 in Human Coronary Atherosclerotic Plaques Potential Implications for Inflammation and Plaque Instability. Circulation. 2000; 101(12):1372-8. [PMID:10736279. https://doi.org/10.1161/01.cir.101.12.1372]

47. Vanden B W, Vermeulen L, De Wilde G, De Bosscher K, Boone E, Haegeman G, et al. Signal Transduction by Tumor Necrosis Factor And Gene Regulation of The Inflammatory Cytokine Interleukin-6. Biochem Pharmacol. 2000; 60(8):1185-95. [PMID:11007957.https://doi.org/10.1016/s0006-2952(00)004123]

48. Tilg $\mathrm{H}$ and Moschen A. Adipocytokines: Mediators Linking Adipose Tissue, Inflammation, and Immunity. Nat Rev Immunol. 2006; 6(10):772-83. [PMID: 16998510. https://doi.org/10.1038/nri1937]

49. Romano M, Sironi M, Toniatti Cet al. Role Of IL-6 And Its Soluble Receptor In Induction Of Chemokines And Leukocyte Recruitment. Immunity. 1997; 6(3):315-25. [PMID: 9075932 https://doi.org/10.1016/s1074-7613(00)80334-9]

50. Wisithphrom K, Murray PE, Windsor LJ. Interleukin- 1 Alpha Alters The Expression of Matrix Metalloproteinases And Collagen Degradation By Pulp Fibroblasts. J Endod .2006; 32(3):186-92. [PMID: 16500223 https://doi.org/10.1016/j.joen.2005.10.055]

51. Hurst SM, Wilkinson TS, McLoughlin RM, Jones S, Horiuchi S, Yamamoto N. Il-6 And Its Soluble Receptor Orchestrate A Temporal Switch In The Pattern Of Leukocyte Recruitment Seen During Acute Inflammation. Immunity 2001; 14(6):705-14. [PMID: 11420041. https://doi.org/10.1016/s1074-7613(01)00151-0]

52. Fan Y, Ye J, Shen F, Zhu Y, Yeghiazarians Y, Zhu W. Interleukin-6 Stimulates Circulating Blood-Derived Endothelial Progenitor Cell Angiogenesis In Vitro. J Cereb Blood Flow Metab. 2008; 28(1):90-8. [PMID: 17519976. https://doi.org/10.1038/sj.jcbfm.9600509]

53. Wang Z, Castresana MR, Newman WH. NF-kB Is Required For TNFAlpha-Directed Smooth Muscle Cell Migration. FEBS Lett. 2001; 508(3):360-4. [PMID: 11728452 https://doi.org/10.1016/s00145793(01)03109-x]
54. Ikeda U, Ikeda M, Oohara Tet al. Interleukin 6 Stimulates Growth of Vascular Smooth Muscle Cells In A PDGF-Dependent Manner. Am J Physiol. 1991; 260(5 Pt 2): H1713-7. [PMID: 1709793 https://doi.org/10.1152/ajpheart.1991.260.5.H1713]

55. Goldblatt P.J., Gohara A.F. Renal vascular diseases: Their relationship to hypertension. In: Didio L.J.A., Motta P.M. (eds)

Basic, Clinical, and Surgical Nephrology. Developments in Nephrology, vol. 8. Springer, Boston, MA. 1985; 8: 157-169. [https://doi.org/10.1007/978-1-4613-2575-8 10]

56. Unger $\mathrm{T}$. The Role of the Renin-Angiotensin System in the Development of Cardiovascular Disease. Am J Cardiol .2002; 89(2A):3A-9A. [PMID: 11835903. https://doi.org/ 10.1016/s0002-9149(01)02321-9]

57. Lerman LO, Nath KA, Rodriguez-Porcel Metal. Increased Oxidative Stress in Experimental Renovascular Hypertension. Hypertension .2001;37(2Pt2):541-6.[PMID:11230332.

https://doi.org/10.1161/01.hyp.37.2.541]

58. Hernández-Presa M, Bustos C, Ortego M, et al. AngiotensinConverting Enzyme Inhibition Prevents Arterial Nuclear FactorKappa B Activation, Monocyte Chemoattractant Protein-1 Expression, And Macrophage Infiltration in A Rabbit Model of Early Accelerated Atherosclerosis. Circulation .1997; 95(6):153241. [PMID: $9118522 \mathrm{https://doi.org/10.1161/01.cir.95.6.1532]}$

59. Itoh $\mathrm{H}$, et al. Multiple Autocrine Growth Factors Modulate Vascular Smooth Muscle Cell Growth Response to Angiotensin II. J Clin Invest. 1993; $\quad 91$ 2 $168-2274$. [https://doi.org/10.1172/JCI116454]

60. Guo RW, Yang LX, Wang H, Liu B, Wang L. Angiotensin II Induces

\section{Cite this as:}

Tantri NL, Rudijanto A, Samsu N, and Wursito. Differences of Carotid Intima-Media Thickness (CIMT) In Patients with Newly Diagnosed Stage 1 and 2 Hypertension, and Chronic Hypertension Patients with Calcium Channel Blockers (CCB) Therapy or Angiotensin Converting Enzyme (ACE)Inhibitors. Clinical and Research Journal in Internal Medicine, 1.1 (2020): 5-18.

Matrix Metalloproteinase-9 Expression Via A Nuclear FactorKappab-Dependent Pathway in Vascular Smooth Muscle Cells. Regul Pept 2008; 147(1-3):37-44. [PMID:18252266. https://doi.org/10.1016/j.regpep.2007.12.005]

61. Al-Daghri NM, Al-Attas OS, Alokail MS, et al. Gender-Specific Associations Between Insulin Resistance, Hypertension, And Markers of Inflammation Among Adult Saudis with and Without Diabetes Mellitus Type 2. Advances in Medical Sciences 2010; 55(2):179-85. [PMID: 21163756 https://doi.org/10.2478/v10039-010-0052-1]

62. Grund, SM. Obesity, Metabolic Syndrome, and Cardiovascular Disease. The Journal of Clinical Endocrinology \& Metabolism. 1989; 89(6):2595-600. [PMID: 15181029.

https://doi.org/10.1210/ic.2004-0372]

63. Bruunsgaard H. Physical Activity and Modulation of Systemic LowLevel Inflammation. J. Leukoc. Biol 2005; 78(4):81935.[PMID:16033812. https://doi.org/10.1189/jlb.0505247]

64. Sipilä K, Moilanen L, Nieminen T, et al. Metabolic Syndrome and Carotid Intima-Media Thickness in The Health 2000 Survey. Atherosclerosis. 2009; 204: 204(1):276-81. [PMID:
[P: 18848324.https://doi.org/10.1016/j.atherosclerosis.2008.08.029 ]

65. Mathieu P, P Pibarot, and JP Després. Metabolic Syndrome: The Danger Signal in Atherosclerosis. Vascular Health and Risk Management. 2006; 2: 285-302. [PMID: 17326334]

66. Kandil ME, Anwar G, Fatouh A, Salama N, et al. Relation between Serum Homocysteine and Carotid Intima-Media Thickness in Obese Egyptian Children. Journal of Clinical and Basic Cardiology. 2010; 13:8-11. [Corpus ID: 55710339] 
67. Thomas R, et al. Intima-Media Thickness in Childhood Obesity, Relations to Inflammatory Markers, Glucose Metabolism, And Blood Pressure. Metabolism. 2006; 55: 113-8 [https://doi.org/10.1016/j.metabol.2005.07.016]

68. Li S, Chen W, Srinivasan SR, Bond MG, Tang R, Urbina EM, et al. Childhood Cardiovascular Risk Factors and Carotid Vascular Changes in Adulthood the Bogalusa Heart Study. JAMA. 2003; 290(17):2271-6. [PMID: 14600185. https://doi.org/10.1001/jama.290.17.2271]

69. Steinberg D. Atherogenesis in Perspective: Hypercholesterolemia and Inflammation as Partner in Crime. Nat Med. 2002; 8(11):12117. [PMID: 12411947 https://doi.org/10.1038/nm1102-1211]

70. Steinberg D. Conner Memorial Lecture. Oxidative modification of LDL and atherogenesis. Circulation. 1997;95(4):106271.[PMID:9054771. https://doi.org/10.1161/01.cir.95.4.1062]

71. Itabe H. Oxidative Modification of LDL: Its Pathological Role in Atherosclerosis. Clin Rev Allerg Immunol. 2009; 37(1):4-11 [PMID: 18987785. https://doi.org/10.1007/s12016-008-8095-9]

72. Itabe H, Ueda M. Measurement of Plasma Oxidized Low-Density Lipoprotein and its Clinical Implications. J Atheroscler Thromb. 2007; 14(1):1-11. 17332686. https://doi.org/10.5551/jat.14.1]

73. Nauck M, Warnick GR, Rifai N. Methods for Measurement of LDLCholesterol: A Critical Assessment of Direct Measurement by Homogeneous Assays versus Calculation. Clinical Chemistry. 2002; 48(2):236-54. [PMID: 11805004]

74. Lester C, et al. Atherosclerotic Assault. Eukaryon, 2006. 2: p. 40-46.

75. Jawien J. New Insight into Immunological Aspect of Atherosclerosis. Archiwum Medycyny Wewnetrznej 2008; 118: 127-131 [PMID:18476459]

76. Bots ML, Baldassarre D, Simon A, de Groot E, O'Leary DH, Riley W et al. Carotid Intima-Media Thickness And Coronary Atherosclerosis: Weak Or Strong Relations? European Heart Journal 2007; 28(4):398-406 [PMID: 17277033. https://doi.org/10.1093/eurheartj/ehl482]

77. Nissen SE, Tuzcu EM, Libby P, et al. Effect of Antihypertensive Agents on Cardiovascular Events in Patients with Coronary Disease and Normal Blood Pressure the CAMELOT Study: A Randomized Controlled Trial. JAMA 2004; 292(18):2217-25. [PMID:15536108.https://doi.org/10.1001/jama.292.18.2217] 